\title{
Therapy-Induced MHC I Ligands Shape Neo-Antitumor CD8 T Cell Responses during Oncolytic Virus-Based Cancer Immunotherapy
}

\author{
J. Patrick Murphy $\AA^{\uparrow} \dagger$, Youra Kim ${ }^{\pi}, \dagger$, Derek R. Clements ${ }^{\dagger}$, Prathyusha Konda ${ }^{\ddagger}$, Heiko \\ Schuster $§, \|$, Daniel J. Kowalewski§ ${ }^{\S}$, , Joao A. Paulo ${ }^{\perp}$, Alejandro M. Cohen ${ }^{\#, \nabla}$, Stefan \\ Stevanovic $§$, Steven P. Gygi ${ }^{\perp}$, Shashi Gujar ${ }^{\star}, \dagger, \neq, \otimes$ \\ †Department of Pathology, Dalhousie University, Halifax, Nova Scotia B3H 4R2, Canada \\ ¥Department of Microbiology and Immunology, Dalhousie University, Halifax, Nova Scotia B3H \\ 4R2, Canada \\ \#Department of Biochemistry, Dalhousie University, Halifax, Nova Scotia B3H 4R2, Canada \\ ${ }^{\nabla}$ Proteomics Core Facility, Dalhousie University, Halifax, Nova Scotia B3H 4R2, Canada \\ ${ }^{\otimes}$ Department of Biology, Dalhousie University, Halifax, Nova Scotia B3H 4R2, Canada \\ §Department of Immunology, Interfaculty Institute for Cell Biology, University of Tübingen, 72074 \\ Tübingen, Germany \\ "Immatics Biotechnologies GmbH, 72076 Tübingen, Germany \\ ${ }^{\perp}$ Department of Cell Biology, Harvard Medical School, Boston, Massachusetts 02115, United \\ States
}

\section{Abstract}

Oncolytic viruses (OVs), known for their cancer-killing characteristics, also overturn tumorassociated defects in antigen presentation through the MHC class I pathway and induce protective neo-antitumor CD8 T cell responses. Nonetheless, whether OVs shape the tumor MHC-I ligandome remains unknown. Here, we investigated if an $\mathrm{OV}$ induces the presentation of novel MHC I-bound tumor antigens (termed tumor MHC-I ligands). Using comparative mass spectrometry (MS)-based MHC-I ligandomics, we determined differential tumor MHC-I ligand expression following treatment with oncolytic reovirus in a murine ovarian cancer model. In vitro, we found that reovirus changes the tumor ligandome of cancer cells. Concurrent multiplexed quantitative proteomics revealed that the reovirus-induced changes in tumor MHC-I ligand presentation were mostly independent of their source proteins. In an in vivo model, tumor MHC-I ligands induced by reovirus were detectable not only in tumor tissues but also the spleens (a

Corresponding Author: shashi.gujar@dal.ca.

IJ.P.M. and Y.K. contributed equally.

The authors declare no competing financial interest.

Quantitative data sets have been made available at Mendeley Data (DOI: 10.17632/t5xb48z959.1). Proteomics data have been submitted to the PRIDE repository, accession \#PXD013066.

Supporting Information

The Supporting Information is available free of charge on the ACS Publications website at DOI: 10.1021/acs.jproteome.9b00173. 
source of antigen-presenting cells) of tumor-bearing mice. Most importantly, therapy-induced MHC-I ligands stimulated antigen-specific IFN $\gamma$ responses in antitumor CD8 $\mathrm{T}$ cells from mice treated with reovirus. These data show that therapy-induced MHC-I ligands may shape underlying neo-antitumor CD8 $\mathrm{T}$ cell responses. As such, they should be considered in strategies promoting the efficacy of OV-based cancer immunotherapies.

\section{Graphical Abstract}

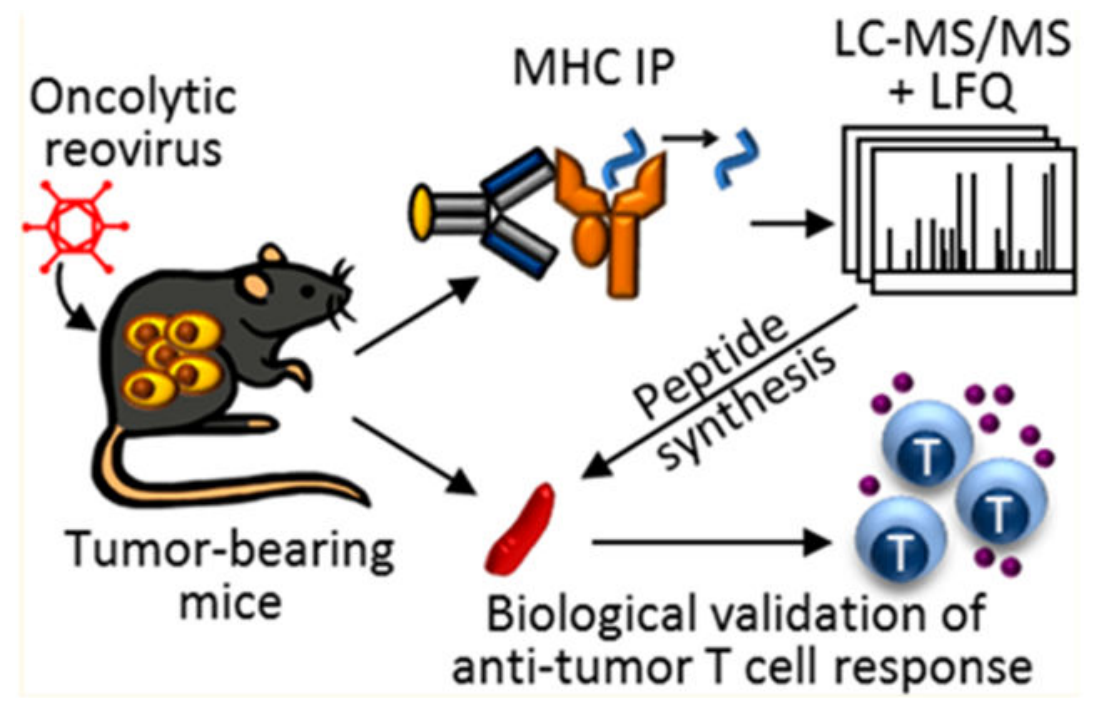

\section{Keywords}

oncolytic virus; reovirus; cancer immunotherapy; mass spectrometry; MHC ligandome; CD8 T cell epitopes; antitumor immunity

\section{- INTRODUCTION}

Therapy-induced antitumor immune responses correlate with better cancer outcomes and thus are highly desired in clinics. ${ }^{1-3}$ Immunotherapies, administered either alone or in combination with conventional therapies, focus on promoting antitumor CD8 T cell responses as the presence of CD8 T cells predicts better clinical outcomes from many of the commonly occurring cancers. ${ }^{4,5}$ Furthermore, immunotherapies like immune checkpoint blockade with anti-PD-1 and anti-CTLA-4 antibodies promote neo-CD8 T cell expansion, which otherwise remain undetectable in nontreated cancer patients. ${ }^{1,6,7}$ These therapyinduced CD8 T cell responses can recognize and target cancer cells and also establish protection against relapse. ${ }^{6,8,9}$ As the activation of CD8 T cells is defined by the epitopes presented in MHC class I molecules (also known as MHC-I ligands), the tumor MHC-I ligandome shapes antitumor CD8 $\mathrm{T}$ cell responses. The potential role of therapy-driven MHC-I ligandome changes is poorly understood.

Reovirus, in its natural form, preferentially replicates in and kills cancer cells and is thus considered an oncolytic virus (OV) leading to several clinical trials for its use in cancer treatment. Reovirus also induces potent antitumor CD8 $\mathrm{T}$ cell immune responses, in part by 
overturning several tumor-associated immune evasion mechanisms. ${ }^{10-19}$ This is manifested by a localized release of cytokines within the tumor microenvironment, leading to the activation and recruitment of various innate and adaptive immune cells. ${ }^{20,21}$ In addition, antigen-presenting cells that ingest cell debris released during oncolysis may activate tumor antigen-specific CD8 T cells. ${ }^{21,22} \mathrm{We}$ have previously demonstrated that reovirus OV therapy enhances the expression of proteins involved in antigen processing (e.g., TAP1, TAP2) and presentation (e.g., MHC-I, $\beta 2$-microglobulin) in tumors of various cancer types. ${ }^{23,24}$ Furthermore, using cancer cells expressing ovalbumin as a surrogate tumor-associated antigen, we have demonstrated reovirus-mediated enhancement of tumor antigen-specific CD8 T cell immunity. ${ }^{23}$ This robust oncolytic virus-mediated antitumor CD8 T cell immunity can be further invigorated by genetically engineering OVs to express immunostimulatory transgenes, ${ }^{25}$ adding immune checkpoint inhibitors, ${ }^{26,27}$ or combining with chemotherapeutic drugs. ${ }^{28}$

Our laboratory has recently reported MHC-I ligandome changes in response to the chemotherapeutic drug doxorubicin. ${ }^{29}$ Although both preferential tumor replication and increased antigen presentation by OVs are well established, whether OVs also change the tumor MHC-I ligandome has not been explored. Here, we used MHC-I immunoprecipitation and LC-MS/MS with label-free quantitation to determine oncolytic reovirus-induced MHC-I ligands. We found that oncolytic reovirus induces new MHC-I ligands in tumor cells in vitro and in vivo, and from spleens (a source of antigen-presenting cells) of tumor-bearing animals. Quantitative proteomic analysis of virus-infected cancer cells revealed that reovirus-induced changes within the tumor MHC-I ligandome occur mostly independent of their source proteins. Most importantly, IFN $\gamma$ assays showed that these therapy-induced tumor MHC-I ligands are immunogenic. Together, these findings highlight the importance of considering the effect of therapies such as OVs on the tumor MHC-I ligandome. The data provide rationale for exploiting the OV-induced tumor MHC-I ligands for cancer immunotherapies due to OV's preferential replication in tumors.

\section{- EXPERIMENTAL SECTION}

\section{Reovirus, Cell Lines, and Reagents}

Reovirus (serotype 3, Dearing strain) was cultured, amplified, and isolated using a previously established protocol. ${ }^{10}$ A mouse ovarian surface epithelial cell line (MOSE, clone ID8) was obtained from Edith Lord (University of Rochester, Rochester, NY), ${ }^{30}$ and grown at $37{ }^{\circ} \mathrm{C}, 5 \% \mathrm{CO}_{2}$ in DMEM containing $10 \%$ fetal bovine serum, $1 \times$ sodium pyruvate, $1 \times$ nonessential amino acids, and $1 \times$ Anti-Anti (all obtained from Invitrogen, Carlsbad, CA). Functional grade purified antimouse CD28 (37.51) was from BioLegend (San Diego, CA). Purified antimouse MHC-I antibodies were produced in-house from hybridoma clones B22.249 ( $\mathrm{H}-2 \mathrm{D}^{\mathrm{b}}$ specific) and $\mathrm{Y} 3\left(\mathrm{H}-2 \mathrm{~K}^{\mathrm{b}}\right.$ specific). For validation experiments, peptides were purchased from JPT Peptide Technologies (Berlin, Germany). An antimouse IFN $\gamma$ DuoSet ELISA kit was purchased from R\&D Systems (Minneapolis, MN). 


\section{MHC-I Peptide Isolation and Mass Spectrometry Analysis}

MHC-I peptide immunoprecipitation was conducted for the mouse ID8 cell line as previously described. ${ }^{31}$ In brief, $1 \times 10^{8}$ cells for each treatment group (nontreated, IFN- $\gamma$ treated, and reovirus-treated) were lysed in PBS containing 0.4\% CHAPS and minicomplete protease inhibitor tablets (Roche, Indianapolis, IN). MHC-I proteins were precipitated from the cell lysates using $2 \mathrm{mg}$ of anti-MHC-I antibody (both $\mathrm{H}-2 \mathrm{D}^{\mathrm{b}}$ and $\mathrm{H}-2 \mathrm{~K}^{\mathrm{b}}$ for mouse) coupled to $80 \mathrm{mg}$ of CNBr-activated Sepharose 4B resin (Uppsala, Sweden). Following overnight incubation in $10 \mathrm{~mL}$ glass tubes at $4{ }^{\circ} \mathrm{C}$, bound MHC-I proteins and peptides were washed with $40 \mathrm{~mL}$ of PBS, then $30 \mathrm{~mL}$ of Milli-Q water, and peptides were eluted from the antibody-resin by acid treatment (eight times with $200 \mu \mathrm{L}$ of $0.2 \%$ trifluoroacetic acid [TFA]). Eluates were purified by ultrafiltration through $3 \mathrm{kDa}$ molecular weight cutoff filters (Millipore, Cork, Ireland), and then the filtrates were lyophilized and desalted using Stage-tips.

Lyophilized peptides were solubilized in $12 \mu \mathrm{L}$ of $1 \%$ formic acid and analyzed by LCMS/MS. For each antibody eluate, an aliquot of $1 \mu \mathrm{L}$ of peptides was injected onto a $75 \mu \mathrm{m}$ $\times 30 \mathrm{~cm}$ column (New Objective, Woburn, MA) self-packed with $4 \mu \mathrm{m}, 90 \AA$ A, Proteo C18 material (Phenomenex, Torrance, $\mathrm{CA}$ ). Online chromatography was performed using a Dionex Ultimate 3000 UHPLC (Thermo Scientific, San Jose, CA) at a flow rate of $300 \mathrm{~nL} /$ min. Peptides were separated and eluted into the mass spectrometer using a gradient of 3 to $35 \%$ acetonitrile ( $0.1 \%$ formic acid) over $65 \mathrm{~min}$, followed by $5 \mathrm{~min}$ at $95 \%$ acetonitrile (0.1\% formic acid). MS was performed using an Orbitrap Velos Pro (Thermo Fisher Scientific, San Jose, CA) operated in data-dependent mode. Survey scans (MS1) were performed using the Orbitrap over a scan range of 350-650 m/z and resolution setting of 60 000. A lock mass of $445.12003 \mathrm{~m} / \mathrm{z}$ was used to achieve internal mass calibration. On the basis of MS1 scans, MS2 scans were performed using the ion trap, selecting the top 10 most intense precursor (MS1) ions for fragmentation by collision-induced dissociation (CID) at $35 \%$ collision energy with a precursor isolation window of $2 \mathrm{~m} / \mathrm{z}$. MS2 scans were only collected on peptides with charge states of $2^{+}$or $3^{+}$with a minimum MS1 intensity of 50 counts. Advanced gain control (AGC) settings were $5 \times 10^{5}$ for Orbitrap scans and $2 \times 10^{5}$ for ion trap scans.

\section{MHC-I Peptide Identification}

MHC-I peptides were identified using a previously described targeted search strategy. ${ }^{32}$ Briefly, MHC-I peptides were predicted from all mouse proteins for the $\mathrm{H}-2 \mathrm{D}^{\mathrm{b}}$ and $\mathrm{H}-2 \mathrm{~K}^{\mathrm{b}}$ alleles using NetMHC with a rank cutoff of $2 \%$ and these peptides were used to create a FASTA database. MS/MS data were searched using Sequest with "no cleavage" enzyme specificity with an MS1 tolerance of 5 ppm and MS2 tolerance of 0.5 Da. False discovery rates were controlled to 5\% using Percolator. Searches were implemented in Proteome Discoverer (PD) version 2.2 (Thermo Fisher Scientific, San Jose, CA). Label-free quantitation (LFQ) was also implemented in PD version 2.2 using the Minora peak alignment algorithm. All peptides were normalized based on the summed peptide intensity for the entire sample. 


\section{Protein Extraction, Digest, and TMT Labeling of ID8 Cells}

Cells were scraped into $2 \mathrm{~mL}$ of lysis buffer containing $2 \%$ SDS, $150 \mathrm{mM} \mathrm{NaCl}, 50 \mathrm{mM}$

Tris (pH 8.5), $5 \mathrm{mM}$ DTT, and 1 tablet of protease inhibitor (Sigma-Aldrich, St. Louis, MO) per $10 \mathrm{~mL}$ of buffer. Samples were homogenized with an Omni homogenizer (Omni International, Kennesaw, GA) with 3 cycles of $12 \mathrm{~s}$, with cooling on ice between cycles, plus sonication with probe sonication. Samples were incubated at $56{ }^{\circ} \mathrm{C}$ for $30 \mathrm{~min}$, cooled, then cysteines were alkylated using $14 \mathrm{mM}$ iodoacetamide, and protein was purified by methanolchloroform precipitation. Proteins were dried then resolubilized in $1.5 \mathrm{~mL}$ of $8 \mathrm{M}$ urea, 50 $\mathrm{mM}$ Tris, $\mathrm{pH} 8.8$ then protein content in the samples was measured using a BCA assay (Thermo Fisher Scientific, San Jose, CA). An aliquot of $100 \mu \mathrm{g}$ of protein was diluted to 1.5 $\mathrm{M}$ urea, digested for $4 \mathrm{~h}$ with trypsin (Promega, Madison, WI) then again overnight (both at a ratio of 1:100 trypsin:protein) at $37^{\circ} \mathrm{C}$. The $\mathrm{pH}$ of the digest was adjusted to $<3$ using formic acid and peptides were desalted using $60 \mathrm{mg}$ solid phase Oasis HLB extraction cartridges (Waters, Milford, MA) then lyophilized. Peptides were resuspended in $100 \mu \mathrm{L}$ of $100 \mathrm{mM}$ HEPES, 30\% acetonitrile and $10 \mu \mathrm{L}$ of TMT10 reagents (Thermo Fisher Scientific, San Jose, CA) prealiquoted at a concentration of $20 \mu \mathrm{g} / \mathrm{mL}$ in anhydrous acetonitrile. The reaction was quenched with $0.5 \%$ hydroxylamine (Sigma-Aldrich, St. Louis, MO), mixed equally, desalted using a $60 \mathrm{mg}$ solid phase Oasis HLB extraction cartridge (Waters, Milford, MA), and lyophilized. Peptides were fractionated using an Onyx monolithic $100 \times$ $4.6 \mathrm{~mm} \mathrm{C18}$ column (Phenomenex, Torrance, CA) using a flow rate of $800 \mu \mathrm{L} / \mathrm{min}$, with a gradient of 5-40\% acetonitrile ( $10 \mathrm{mM}$ ammonium formate, $\mathrm{pH}$ 8) applied over $60 \mathrm{~min}$ using an Agilent 1100 pump (Agilent Technologies, Santa Clara, CA). Twelve fractions were collected and desalted using homemade Stage-tips packed with Empore C18 extraction material (Sigma-Aldrich, St. Louis, MO) as previously described, ${ }^{33}$ then lyophilized and subjected to LC-SPS-MS3.

\section{LC-SPS-MS3, Protein Identification and Quantitation}

Labeled peptides were separated by online nLC similarly to the MHC-I peptides. SPS-MS3 was performed on the Orbitrap Fusion (Thermo Fisher Scientific, San Jose, CA). MS1 scanswere acquired over an $\mathrm{m} / \mathrm{z}$ range of $350-1400,120 \mathrm{~K}$ resolution, AGC target of $5 \times 10^{5}$, and maximum injection time of $100 \mathrm{~ms}$. MS2 scans were acquired on the 10 most-abundant MS1 ions of charge state 2-8 using an isolation window of $0.7 \mathrm{Th}$, CID activation with a collision energy of 35\%, rapid scan rate, AGC target of 20000 , dynamic exclusion for $120 \mathrm{~s}$, and maximum injection time of $150 \mathrm{~ms}$. MS3 scans were acquired using SPS of 10 isolation notches, $\mathrm{m} / \mathrm{z}$ range of $100-1000,50 \mathrm{~K}$ resolution, AGC target of $2.5 \times 10^{5}$, HCD activation at $65 \%$, and maximum injection time of $200 \mathrm{~ms}$.

Mass spectrometry data files were converted to mzXML using a modified version of ReadW.exe. MS2 spectra were searched against the mouse UniProt database (downloaded August, 2011) using Sequest (Ver28) ${ }^{34}$ concatenated with a reovirus protein sequence database. TMT was set as a fixed modification (229.162932) on lysine residues and peptide $\mathrm{N}$-termini, and carbamidomethylation (15.99492) as a fixed modification on cysteine. The allowable precursor mass tolerance was $10 \mathrm{ppm}$ and product ion mass tolerance was $1 \mathrm{Da}$. False positive rates were controlled using the target-decoy approach ${ }^{35}$ with a concatenated reversed database employing linear discriminant analysis to distinguish correct and incorrect 
peptide identifications based on XCorr, $\Delta \mathrm{CN}$, peptide length, and charge state. Peptides were grouped into proteins and their multiplied linear discriminant analysis probabilities were used to sort proteins and filter to a $1 \%$ maximum false discovery rate. The sum of all reporter ion summed signal-to-noise $(\mathrm{S} / \mathrm{N})$ values for peptides matching each protein was used for protein quantitation.

\section{In Vivo Experimental Procedures}

All in vivo experimental procedures were approved by the Ethics Committee at Dalhousie University, Halifax, Nova Scotia, Canada. Six to eight week old female wildtype C57BL/ 6 mice were obtained from Charles River Laboratories (Montreal, QC, Canada). Mice were injected as follows: reovirus $\left(5 \times 10^{8}\right.$ plaque forming unit [PFU], intraperitoneally [i.p.]), ID8 $\left(3 \times 10^{6}\right.$ cells, i.p.). ID8 tumor-bearing mice were injected with reovirus at 35 days post tumor implantation. Spleens and tumors were harvested at 7-10 days post reovirus injection.

\section{T Cell IFN $\gamma$ Assay}

Spleens were harvested from mice and mechanically disrupted using the end of a syringe plunger. Cells were filtered through a $40 \mu \mathrm{m}$ cell strainer and treated with red blood celllysing ammonium-chloride-potassium (ACK) buffer. The resulting single-cell suspension of splenocytes was cultured in RPMI 1640 containing 1\% (v/v) Glutamax, 10\% fetal bovine serum, $1 \times$ sodium pyruvate, $1 \times$ nonessential amino acids, and $1 \times$ Anti-Anti (all obtained from Invitrogen, Carlsbad, CA) for in vitro stimulation. Splenocytes $\left(1 \times 10^{6}\right.$ cells/well in a round-bottom 96-well plate) were cultured in the presence of peptide $(10 \mu \mathrm{g} / \mathrm{mL})$ and purified antimouse CD28 antibody $(1 \mu \mathrm{g} / \mathrm{mL})$ for $48 \mathrm{~h}$. The concentration of IFN $\gamma$ in the supernatant was assessed using the IFN $\gamma$ ELISA kit (R\&D Systems, Minneapolis, MN) following the manufacturer's instructions.

\section{Statistical Analysis}

Statistical analysis of all MHC-I and proteomic data was performed in R. F-tests were performed on the quantitative MHC-I and proteome data using the genefilter package. Histogram ridge plots were generated using ggridges, position-specific frequency matrices (PSFM) were calculated using peptools, sequence logos were generated using ggseqlogo, and heatmaps were generated using pheatmap $\mathrm{R}$ packages. One-way ANOVA with Bonferroni post-test or a two-tailed Student's t-test with $95 \%$ confidence interval was used for statistical analyses where indicated. $p$-values were corrected for multiple hypothesis (adjusted $p$-values) using Benjamini-Hochberg and represented as follows: $\mathrm{ns}=p>0.05,{ }^{*} p$ $\leq 0.05, * * p \leq 0.01$, and $* * * p \leq 0.001$.

\section{- RESULTS AND DISCUSSION}

\section{Oncolytic Reovirus Induces the Expression of Otherwise Low-Abundant MHC-I Ligands in Mouse Ovarian Cancer Cells in Vitro}

On the basis of our previous findings that reovirus (type 3 Dearing strain) initiates CD8 T cell antitumor immunity, ${ }^{23,24}$ we first sought to determine whether reovirus infection differentially modifies MHC-I ligandome constituents in cancer cells grown in vitro. Mouse ID8 ovarian cancer cells (C57BL/6 background; $\mathrm{H}-2 \mathrm{D}^{\mathrm{b}}$ and $\mathrm{H}-2 \mathrm{~K}^{\mathrm{b}}$ MHC class I alleles) 
were untreated (NT), treated with interferon-gamma (IFN $\gamma$, a known inducer of MHC-I expression, used as a positive control), or infected with reovirus at a multiplicity of infection (MOI) of 10 for $24 \mathrm{~h}$. MHC-I peptides were then isolated by MHC-I immunoprecipitation (IP), measured by LC-MS/MS, identified using our recently developed targeted database search approach, ${ }^{32}$ and quantified by label-free quantitation (Figure 1A). This resulted in a data set of 1542 unique $\mathrm{H}-2 \mathrm{D}^{\mathrm{b}}$-specific peptides and 1346 unique $\mathrm{H}-2 \mathrm{~K}^{\mathrm{b}}$-specific peptides, totalling 2888 unique MHC-I peptides matching to 3766 protein accessions. Of these, we obtained label-free quantitation data for $1393(90 \%)$ and $1227(92 \%)$ unique $\mathrm{H}-2 \mathrm{D}^{\mathrm{b}}$-and $\mathrm{H}-2 \mathrm{~K}^{\mathrm{b}}$-specific peptides, respectively (Figure $1 \mathrm{~B}$ ). The majority of the MHC-I ligands identified by our method had NetMHC-predicted ${ }^{36,37}$ binding affinities $₫ 0.5 \%$ rank and, thus, were considered strong binders, confirming the robustness of our MHC IP and search strategy (Figure S1A). In a reference search, not targeted toward MHC-I ligands, we observed 407 unique peptides with NetMHC \% rank $>2$ and some of these were found at a higher abundance following reovirus or IFN $\gamma$ treatment. However, these arise from commonly observed proteins by proteomics (such as AHNAK, TUBB, and S100A11) or derived from reovirus proteins (Figure S1B). These peptides are thus likely degradation products or those with weak MHC-I binding affinity but could be investigated further for immunogenicity. Quantitative data sets have been made available at Mendeley Data (DOI: 10.17632/t5xb48z959.1).

We observed vast changes in MHC-I ligands in response to both IFN $\gamma$ and reovirus, many reaching a level of relative quantitation (above noise) that were as great as the MHC-I peptides derived directly from virus source proteins (Figure 1C). Using IFN $\gamma$ to control for overall increases in antigen presentation machinery allowed us to determine MHC-I peptides specifically induced by reovirus infection. As such, we observed 241 virus-induced (normalized $\log _{2}$ [reovirus/NT] $\geq 1$, adjusted $p$-value $₫$ (0.05) MHC-I ligands which were not induced by IFN $\gamma$, representing $8.3 \%$ of the total MHC-I peptides identified in the experiment (Figure 1D). As expected, Gene ontology (GO) enrichment analysis using the PANTHER Classification System ${ }^{38,39}$ of the source proteins of these specific virus-induced MHC-I ligands showed enrichment of viral defense biological processes (BPs), as well DNA replication, cell cycle, and proteolysis regulation (Figure 1D). These include proteins such as DDX60, ISG15, and NFKB and many other proteins involved in the cell cycle (Figure 1D). Interestingly, we identified 386 virus-induced MHC-I ligands that are also induced by IFN $\gamma$ treatment (Figure 1E). PANTHER analysis of source proteins of these IFN $\gamma /$ reovirusinduced MHC-I ligands revealed enriched GO BP terms such as telomere maintenance, G1/S transition, and ubiquitin-dependent catabolic process (Figure 1E) exemplified by MHC-I peptides from ISG15, GVIN1, IFI47, and OASL2 (Figure 1E). The comparison between virus-induced and IFN $\gamma /$ virus-induced MHC-I ligands indicates that some changes in the MHC-I ligandome constituents are virus-specific, independent of the viral enhancement of antigen presentation. Previous studies have reported changes to the self MHC-I peptidome due to virus infections possibly through IFN signaling. ${ }^{40}$ However, the unique changes in the MHC-I repertoire apart from antigen presentation differences we observed here may offer therapeutic advantages if the preferential targeting of OV in tumors can be harnessed. 


\section{Virus-Induced Alterations in the Tumor MHC-I Ligandome Are Largely Independent of Their Source Proteins}

MHC-I peptide presentation is proposed to correspond to source protein abundance. ${ }^{41} \mathrm{We}$ therefore next determined whether reovirus-induced alterations in the tumor MHC-I ligands are due to changes at the proteome level. To explore the MHC-I ligand and proteome relationship quantitatively, we performed 10-plex tandem mass tag (TMT)-based quantitative proteomics ${ }^{42}$ on virus-infected ID8 cells over a 48-h time course with two MOI of reovirus (1 and 10) (Figure 2A). In total, we quantified 6561 proteins and observed temporally distinct patterns of protein expression following k-means clustering (Figure 2A). GO annotation analysis using PANTHER of Cluster 1, which contained proteins that increased due to reovirus infection, showed enrichment of proteins involved in virus response, interferon response, and antigen processing (Figure 2B). Similar to the reovirus proteins that we identified (e.g., Lambda1, Mu1; Figure 2C), virus response proteins (e.g., APOL9, CCL5, GBP4, OAS1A; Figure 2D) and antigen presentation proteins (e.g., B2M, H2-D1, TAP1, TAP2; Figure 2E) all showed increased relative intensity over time in response to reovirus. These data confirm results from our previous work showing the effect of reovirus on antigen presentation in ID8 cells. ${ }^{24}$ The remaining proteins (five of the six clusters, representing most of the data set) showed only minor changes, or decreases, in relative intensity over time (Figure 2A). Proteomics data have been submitted to the PRIDE repository, accession \#PXD013066.

To match peptides to potential source proteins, we matched MHC-I peptides to all potential protein accessions from the UniProt database and then determined whether any of those proteins were in our proteomics data set (Figure 3A). This resulted in 1022 (66\%) and 912 $(68 \%)$ respective $\mathrm{H}-2 \mathrm{D}^{\mathrm{b}}$ and $\mathrm{H}-2 \mathrm{~K}^{\mathrm{b}}$ peptides (Figure $3 \mathrm{~B}$ ) with successful matches to the proteome data set. These matches equated to 1070 and 1022 peptide-accession combinations for $\mathrm{H}-2 \mathrm{D}^{\mathrm{b}}$-and $\mathrm{H}-2 \mathrm{~K}^{\mathrm{b}}$-specific peptides, respectively. Comparison of the $\log _{2}$ fold change in MHC-I peptide abundance against the $\log _{2}$ fold change in protein abundance at $48 \mathrm{~h}$ revealed poor correlation between MHC-I peptide presentation and protein abundance (Figure 3C). For example, AALDFKNV from the protein SMC4 was induced 29-fold but showed no difference at the source protein level (Figure 3D). Although most MHC-I peptides indeed showed no protein-level changes, a small fraction of the MHC-I peptides did increase both at the MHC-I peptide and source protein levels (Figure 3C). For example, AALTGTHVL from APOL9B was increased 9.2- and 290-fold at the MHC-I peptide and protein levels, respectively (Figure 3D).

The general lack of correlation between the MHC-I peptide and source protein levels in our data somewhat contrasts with previous studies on peptide presentation and protein abundance. However, our data concern differential measurements rather than overall abundance, which suggests that external effects on protein abundance, such as those affected by virus infection, are not represented by the MHC-I ligandome changes. These data suggest that virus-induced differences in protein cleavage and peptide trimming, as opposed to the synthesis of new proteins, may play a greater role in MHC-I peptide generation during viral infections. To investigate this, we analyzed source protein sequences of reovirus-induced MHC-I peptides compared to unchanged peptides. We observed only minor differences in 
the frequency of amino acid residues ten positions upstream or downstream of these MHC-I peptides, between induced or all other MHC-I peptides in the data set (Figure S2A). There was also no observable difference in the distance to the source protein Nor C-terminus between the induced, unchanging, or repressed MHC-I peptides (Figure S2B). Altogether, our data suggest that MHC-I ligand differences from reovirus infection are not caused by differential protein abundance or peptide cleavage. MHC-I peptide presentation is complex and factors such as protein synthesis rates, turnover, and proteostasis should be investigated in further studies to determine how antigen presentation is governed.

\section{In Vivo, Reovirus Induces Tumor MHC-I Ligands That Are Exclusive to Tumor-Bearing Mice}

Although it has been observed that OVs elicit antitumor immunity, whether induced antigens drive this immune response remains unexplored. Further, a major characteristic of OVs is their preferential replication in tumors as a result of their ability to hijack the active replicative machinery of cancer cells. ${ }^{43}$ Having established that reovirus alters the MHC-I ligandome in an in vitro setting, we next sought to understand whether the virus preferentially alters the MHC-I ligandome in tumors and whether this is reflected in MHC-I ligands of immune cells. To do this, spleens and/or tumors from nontreated or reovirustreated, naïve or ID8 tumor-bearing (TB) mice were collected and analyzed by MHC-I immunoprecipitation and LC-MS/MS with LFQ (Figure 4A). In this experiment, we quantified 2447 and $1681 \mathrm{H}-2 \mathrm{D}^{\mathrm{b}}$ and $\mathrm{H}-2 \mathrm{~K}^{\mathrm{b}}$ peptides, respectively, matching to 6170 protein accessions in the search database (Figure 4B). Consistent with recently reported differences in tissue-specificity of mouse MHC-I ligands ${ }^{44}$ we observed only partial overlap with the in vitro experiment, whereby 1071 (20\% of the 5199 total peptides between the two experiments) of the in vitro-identified MHC-I peptides were not quantified in vivo (Figure S3A). Importantly, preferential tumor replication of reovirus was indeed reflected in the MHC-I ligandome. We observed far greater differential MHC-I abundance in the TB mice (both in the spleen and the tumor) than in the naive mice. For example, 2.9- and 7.8-fold more $\mathrm{H}-2 \mathrm{D}^{\mathrm{b}}$ peptides were induced by reovirus in the spleen and tumor, respectively, of TB mice (normalized $\log _{2}\left[\right.$ reovirus/NT]) $\geq 1.0$, adjusted p-value $₫ 0.05$ ) (Figure $4 \mathrm{~B}$ ). $\mathrm{H}-2 \mathrm{~K}^{\mathrm{b}}$ peptides showed this same effect whereby 6.4- and 14-fold more peptides were induced in the TB mice by reovirus at the spleen and tumor, respectively, than in the naive mice (Figure 4B). To further illustrate the preferential reovirus infection in tumors, we directly compared reovirus-induced MHC-I ligands across the experiment. Of the MHC-I peptides that were significantly induced (normalized mean $\log _{2}[$ reovirus/NT]) $\geq 1.0$, adjusted p-value $₫$ (0.05) at the tumor, approximately 50\% were also induced in the spleen of TB mice but very few of these were induced in the naïve mice (Figure S3B). Representative label-free quantitation data for several of these MHC-I peptides induced in both the spleen and tumor, tumor-only, or reovirus-derived are exemplified in Figure 4C. These data suggest that TB mice display a reovirus-induced tumor MHC-I ligandome that is not found in reovirus-treated naïve mice, PBS-treated naïve mice, or PBS-treated TB mice.

\section{Reovirus-Induced Tumor MHC-I Ligands Contain Biologically Active Antitumor CD8 T Cell Epitopes}

Having determined the preferential reovirus-induced MHC-I ligand changes in the ID8 tumor, we next investigated whether these therapy-induced MHC ligands elicit antitumor 
CD8 $\mathrm{T}$ cell responses. To do this, we chose 16 highly virus-induced tumor MHC-I ligands (normalized $\log _{2}[$ reovirus/NT]) $\geq 3.0$, adjusted $p$-value $\$$ ).05) across a range of NetMHC \% rank (but all $\mathcal{2} \%$ rank) and peptide spectrum matches (PSMs), and excluding those that were also induced in the naive spleen (Figure 5A). These highly induced peptides were essentially absent in the untreated tumors and 13 of them were also induced in the spleen of TB mice (Figure 5B). These 16 peptides were synthesized and their capacity to elicit CD8 T cell responses in splenocytes of untreated and reovirus-treated TB mice was measured by IFN $\gamma$ ELISA in the presence of costimulation with an anti-CD28 antibody. We observed no IFN $\gamma$ response in splenocytes from reovirus-treated mice in the absence of any of the peptides or with anti-CD28 costimulation alone. In a validation screen, four of these peptides (GIIRFLIGF, INYVVAHV, STLSHVVL, and RSYRFMVM) produced strong responses $(>150 \mathrm{pg} / \mathrm{mL})$ in splenocytes of reovirus-infected TB mice, nearly equaling IFN $\gamma$ production of the concanavalin A positive control (Figure 5C). Taken together, these data strongly suggest that reovirus-induced tumor MHC-I ligands can activate CD8 T cells. Although these MHC-I peptides are nonmutated self-peptides, they are absent without infection and thus may be immunogenic. These results support findings that the breadth of antitumor CD8 T cell immune response is majorly dictated by tumor-associated antigens (TAAs). ${ }^{45,46}$ Most importantly, our data show that OV-induced MHC-I ligands may shape the therapy-induced neo-antitumor CD8 T cell responses.

\section{- CONCLUSIONS}

Similar to the already proposed implications for cancer neoepitopes,,${ }^{6,7}$ our data suggest that another promising strategy to enhance antitumor $\mathrm{CD} 8 \mathrm{~T}$ cell immunity could be to exploit the OV therapy-induced tumor MHC-I ligandome. The exclusive identification of virusinduced MHC-I peptides in TB mice demonstrates the potential for therapy-induced human HLA-ligand-based vaccines to be developed and used in combination with OVs currently being tested in clinical trials. Finally, induced MHC-I ligands may be valuable not only for OV-based cancer therapies but other treatments that induce neo-antitumor CD8 T cell responses (e.g., doxorubicin, and checkpoint inhibitors such as anti-PD-1 and anti-CTLA-4 antibodies $^{6}$ ), ultimately leading to next generation cancer immunotherapies.

\section{Supplementary Material}

Refer to Web version on PubMed Central for supplementary material.

\section{- ACKNOWLEDGMENTS}

This work was supported by grants from the Canadian Cancer Society Research Institute (CCSRI), and Canadian Institutes of Health Research (CIHR) to S.G. Authors Y.K. and D.R.C. are supported by the CIHR Doctoral award. J.P.M. was previously supported through the Cancer Research Training Program (CRTP) of Beatrice Hunter Cancer Research Institute (BHCRI). Work by J.A.P. was funded in part by NIH/NIDDK grant K01 DK098285. We acknowledge Devanand Pinto and Ken Chisholm (National Research Council) for their support. S.G. is supported by Dalhousie Medical Research Foundation (DMRF).

\section{REFERENCES}

(1). Gravitz L Cancer immunotherapy. Nature 2013, 504, S1. [PubMed: 24352357] 
(2). Wei SC; Duffy CR; Allison JP. Fundamental mechanisms of immune checkpoint blockade therapy. Cancer Discovery 2018, 8, 1069-1086. [PubMed: 30115704]

(3). Galluzzi L; Buqué A; Kepp O; Zitvogel L; Kroemer G Immunogenic cell death in cancer and infectious disease. Nat. Rev. Immunol 2017, 17, 97-111. [PubMed: 27748397]

(4). Varn FS; Wang Y; Mullins DW; Fiering S; Cheng C Systematic pan-cancer analysis reveals immune cell interactions in the tumor microenvironment. Cancer Res. 2017, 77, 1271-1282. [PubMed: 28126714]

(5). Sharma P; Allison JP Immune checkpoint targeting in cancer therapy: toward combination strategies with curative potential. Cell 2015, 161, 205-214. [PubMed: 25860605]

(6). Fehlings M; Simoni Y; Penny HL; Becht E; Loh CY; Gubin MM; Ward JP; Wong SC; Schreiber RD; Newell EW Checkpoint blockade immunotherapy reshapes the high-dimensional phenotypic heterogeneity of murine intratumoural neoantigen-specific CD8+ T cells. Nat. Commun 2017, 8, 562. [PubMed: 28916749]

(7). Anagnostou V; Smith KN; Forde PM; Niknafs N; Bhattacharya R; White J; Zhang T; Adleff V; Phallen J; Wali N; Hruban C; Guthrie VB; Rodgers K; Naidoo J; Kang H; Sharfman W; Georgiades C; Verde F; Illei P; Li QK; Gabrielson E; Brock MV; Zahnow CA; Baylin SB; Scharpf RB; Brahmer JR; Karchin R; Pardoll DM; Velculescu VE Evolution of neoantigen landscape during immune checkpoint blockade in non-small cell lung cancer. Cancer Discovery 2017, 7, 264-276. [PubMed: 28031159]

(8). Durgeau A; Virk Y; Corgnac S; Mami-Chouaib F Recent advances in targeting CD8 T-cell immunity for more effective cancer immunotherapy. Front. Immunol 2018, 9, 14. [PubMed: 29403496]

(9). Luksza M; Riaz N; Makarov V; Balachandran VP; Hellmann MD; Solovyov A; Rizvi NA; Merghoub T; Levine AJ; Chan TA; Wolchok JD; Greenbaum BD A neoantigen fitness model predicts tumour response to checkpoint blockade immunotherapy. Nature 2017, 551, 517-520. [PubMed: 29132144]

(10). Coffey MC; Strong JE; Forsyth PA; Lee PW Reovirus therapy of tumors with activated Ras pathway. Science 1998, 282, 1332-1334. [PubMed: 9812900]

(11). Hirasawa K; Nishikawa SG; Norman KL; Alain T; Kossakowska A; Lee PW Oncolytic reovirus against ovarian and colon cancer. Cancer Res. 2002, 62, 1696-1701. [PubMed: 11912142]

(12). Norman KL; Coffey MC; Hirasawa K; Demetrick DJ; Nishikawa SG; DiFrancesco LM; Strong JE; Lee PW Reovirus oncolysis of human breast cancer. Hum. Gene Ther 2002, 13, 641-652. [PubMed: 11916487]

(13). Hirasawa K; Nishikawa SG; Norman KL; Coffey MC; Thompson BG; Yoon CS; Waisman DM; Lee PW Systemic reovirus therapy of metastatic cancer in immune-competent mice. Cancer Res. 2003, 63, 348-353. [PubMed: 12543787]

(14). Wilcox ME; Yang W; Senger D; Rewcastle NB; Morris DG; Brasher PM; Shi ZQ; Johnston RN; Nishikawa S; Lee PW; Forsyth PA Reovirus as an oncolytic agent against experimental human malignant gliomas. J. Natl. Cancer Inst 2001, 93, 903-912. [PubMed: 11416111]

(15). Kilani RT; Tamimi Y; Hanel EG; Wong KK; Karmali S; Lee PWK; Moore RB Selective reovirus killing of bladder cancer in a co-culture spheroid model. Virus Res. 2003, 93, 1-12. [PubMed: 12727337]

(16). Alain T; Hirasawa K; Pon KJ; Nishikawa SG; Urbanski SJ; Auer Y; Luider J; Martin A; Johnston RN; Janowska-Wieczorek A; Lee PWK; Kossakowska AE Reovirus therapy of lymphoid malignancies. Blood 2002, 100, 4146-4153. [PubMed: 12393565]

(17). Lee P; Gujar S Potentiating prostate cancer immunotherapy with oncolytic viruses. Nat. Rev. Urol 2018, 15, 235-250. [PubMed: 29434366]

(18). Gujar S; Pol JG; Kim Y; Lee PW; Kroemer G Antitumor benefits of antiviral immunity: an underappreciated aspect of oncolytic virotherapies. Trends Immunol. 2018, 39, 209-221. [PubMed: 29275092]

(19). Twumasi-Boateng K; Pettigrew JL; Kwok YYE; Bell JC; Nelson BH Oncolytic viruses as engineering platforms for combination immunotherapy. Nat. Rev. Cancer 2018, 18, 419-432. [PubMed: 29695749] 
(20). Schulz O; Diebold SS; Chen M; Naslund TI; Nolte MA; Alexopoulou L; Azuma Y; Flavell RA; Liljestrom P; Sousa CRE Toll-like receptor 3 promotes crosspriming to virus-infected cells. Nature 2005, 433, 887. [PubMed: 15711573]

(21). Lichty BD; Breitbach CJ; Stojdl DF; Bell JC Going viral with cancer immunotherapy. Nat. Rev. Cancer 2014, 14, 559. [PubMed: 24990523]

(22). Benencia F; Courreges MC; Fraser NW; Coukos G Herpes virus oncolytic therapy reverses tumor immune dysfunction and facilitates tumor antigen presentation. Cancer Biol. Ther 2008, 7, 1194 1205. [PubMed: 18458533]

(23). Gujar SA; Marcato P; Pan D; Lee PW Reovirus virotherapy overrides tumor antigen presentation evasion and promotes protective antitumor immunity. Mol. Cancer Ther 2010, 9, 2924-2933. [PubMed: 20978162]

(24). Gujar S; Dielschneider R; Clements D; Helson E; Shmulevitz M; Marcato P; Pan D; Pan LZ; Ahn DG; Alawadhi A; Lee PW Multifaceted therapeutic targeting of ovarian peritoneal carcinomatosis through virus-induced immunomodulation. Mol. Ther 2013, 21, 338-347. [PubMed: 23299799]

(25). Andtbacka RH; Kaufman HL; Collichio F; Amatruda T; Senzer N; Chesney J; Delman KA; Spitler LE; Puzanov I; Agarwala SS; Milhem M; Cranmer L; Curti B; Lewis K; Ross M ; Guthrie T; Linette GP; Daniels GA; Harrington K; Middleton MR; Miller WH Jr; Zager JS; Ye Y; Yao B; Li A; Doleman S; VanderWalde A; Gansert J; Coffin RS. Talimogene Laherparepvec improves durable response rate in patients with advanced melanoma. J. Clin. Oncol 2015, 33, 2780-2788. [PubMed: 26014293]

(26). Samson A; Scott KJ; Taggart D; West EJ; Wilson E; Nuovo GJ; Thomson S; Corns R; Mathew RK; Fuller MJ; Kottke TJ; Thompson JM; Ilett EJ; Cockle JV; van Hille P; Sivakumar G; Polson ES; Turnbull SJ; Appleton ES; Migneco G; Rose AS; Coffey MC; Beirne DA; Collinson FJ; Ralph C; Alan Anthoney D; Twelves CJ; Furness AJ; Quezada SA; Wurdak H; Errington-Mais F; Pandha H; Harrington KJ; Selby PJ; Vile RG; Griffin SD; Stead LF; Short SC; Melcher AA Intravenous delivery of oncolytic reovirus to brain tumor patients immunologically primes for subsequent checkpoint blockade. Sci. Transl Med 2018, 10, eaam7577. [PubMed: 29298869]

(27). Bourgeois-Daigneault M; Roy DG; Aitken AS; El Sayes N ; Martin NT; Varette O; Falls T; StGermain LE; Pelin A; Lichty BD; Stojdl DF; Ungerechts G; Diallo J; Bell JC Neoadjuvant oncolytic virotherapy before surgery sensitizes triplenegative breast cancer to immune checkpoint therapy. Sci. Transl. Med 2018, 10, eaao1641. [PubMed: 29298865]

(28). Gujar SA; Clements D; Dielschneider R; Helson E; Marcato P; Lee PW Gemcitabine enhances the efficacy of reovirus-based oncotherapy through anti-tumour immunological mechanisms. $\mathrm{Br}$. J. Cancer 2014, 110, 83-93. [PubMed: 24281006]

(29). Murphy JP; Yu Q; Konda P; Paolo J; Jedrychowski M; Kowalewski D; Schuster H; Kim Y; Clements D; Jain A; Stevanovic S; Gygi S; Mancias J; Gujar S Multiplexed relative quantitation with isobaric tagging mass spectrometry reveals class I major histocompatibility complex ligand dynamics in response to doxorubicin. Anal. Chem 2019, 91, 5106. [PubMed: 30779550]

(30). Sorensen EW; Gerber SA; Sedlacek AL; Rybalko VY; Chan WM; Lord EM Omental immune aggregates and tumor metastasis within the peritoneal cavity. Immunol. Res 2009, 45, 185-194. [PubMed: 19253004]

(31). Kowalewski DJ; Stevanovic S Biochemical large-scale identification of MHC class I ligands. Methods Mol. Biol 2013, 960, 145. [PubMed: 23329485]

(32). Murphy JP; Konda P; Kowalewski DJ; Schuster H; Clements D; Kim Y; Cohen AM; Sharif T; Nielsen M; Stevanovic S; Lee PW; Gujar S MHC-I ligand discovery using targeted database searches of mass spectrometry data: implications for T-cell immunotherapies. J. Proteome Res 2017, 16, 1806-1816. [PubMed: 28244318]

(33). Rappsilber J; Ishihama Y Matthias Mann Stop and go extraction tips for matrix-assisted laser desorption/ionization, nano-electrospray, and LC/MS sample pretreatment in proteomics. Anal. Chem 2003, 75, 663-670. [PubMed: 12585499]

(34). Eng JK; McCormack AL; Yates JR An approach to correlate tandem mass spectral data of peptides with amino acid sequences in a protein database. J. Am. Soc. Mass Spectrom 1994, 5, 976-989. [PubMed: 24226387] 
(35). Elias JE; Gygi SP Target-decoy search strategy for increased confidence in large-scale protein identifications by mass spectrometry. Nat. Methods 2007, 4, 207-214. [PubMed: 17327847]

(36). Lundegaard C; Lund O; Nielsen M Accurate approximation method for prediction of class I MHC affinities for peptides of length 8, 10 and 11 using prediction tools trained on 9mers. Bioinformatics 2008, 24, 1397-1398. [PubMed: 18413329]

(37). Karosiene E; Lundegaard C; Lund O; Nielsen M NetMHCcons: a consensus method for the major histocompatibility complex class I predictions. Immunogenetics 2012, 64, 177-186. [PubMed: 22009319]

(38). Thomas PD; Campbell MJ; Kejariwal A; Mi H; Karlak B; Daverman R; Diemer K; Muruganujan A; Narechania A PANTHER: a library of protein families and subfamilies indexed by function. Genome Res. 2003, 13, 2129-2141. [PubMed: 12952881]

(39). Mi H; Dong Q; Muruganujan A; Gaudet P; Lewis S; Thomas PD PANTHER version 7: improved phylogenetic trees, orthologs and collaboration with the Gene Ontology Consortium. Nucleic Acids Res. 2010, 38, D204-D210. [PubMed: 20015972]

(40). Spencer CT; Bezbradica JS; Ramos MG; Arico CD; Conant SB; Gilchuk P; Gray JJ; Zheng M; Niu X; Hildebrand W; Link AJ; Joyce S Viral infection causes a shift in the self peptide repertoire presented by human MHC class I molecules. Proteomics: Clin. Appl 2015, 9, 10351052. [PubMed: 26768311]

(41). Bassani-Sternberg M; Pletscher-Frankild S; Jensen LJ; Mann M Mass spectrometry of human leukocyte antigen class I peptidomes reveals strong effects of protein abundance and turnover on antigen presentation. Mol. Cell. Proteomics 2015, 14, 658-673. [PubMed: 25576301]

(42). Murphy JP; Stepanova E; Everley RA; Paulo JA; Gygi SP Comprehensive temporal protein dynamics during the diauxic shift in Saccharomyces cerevisiae. Mol. Cell. Proteomics 2015, 14, 2454. [PubMed: 26077900]

(43). Pikor LA; Bell JC; Diallo J Oncolytic viruses: exploiting cancer's deal with the devil. Trend. Cancer 2015, 1, 266-277.

(44). Schuster H; Shao W; Weiss T; Pedrioli PGA; Roth P; Weller M; Campbell DS; Deutsch EW; Moritz RL; Planz O; Rammensee H; Aebersold R; Caron E A tissue-based draft map of the murine MHC class I immunopeptidome. Sci. Data 2018, 5, 180157. [PubMed: 30084848]

(45). Laumont CM; Vincent K; Hesnard L; Audemard E; Bonneil E; Javerdure J; Gendron P; Courcelles M; Hardy M; Cote C; Durette C; St-Pierre C; Benhammadi M; Lanoix J; Vobecky S; Haddad E; Lemieux S; Thibault P; Perreault C Noncoding regions are the main source of targetable tumor-specific antigens. Sci. Transl. Med 2018, 10, eaau5516. [PubMed: 30518613]

(46). Zacharakis N; Chinnasamy H; Black M; Xu H; Lu Y; Zheng Z; Pasetto A; Langhan M; Shelton T; Prickett T; Gartner J; Jia L; Trebska-McGowan K; Sommerville RP; Robbins PF; Rosenberg SA; Goff SL; Feldman SA Immune recognition of somatic mutations leading to complete durable regression in metastatic breast cancer. Nat. Med 2018, 24, 724-730. [PubMed: 29867227] 


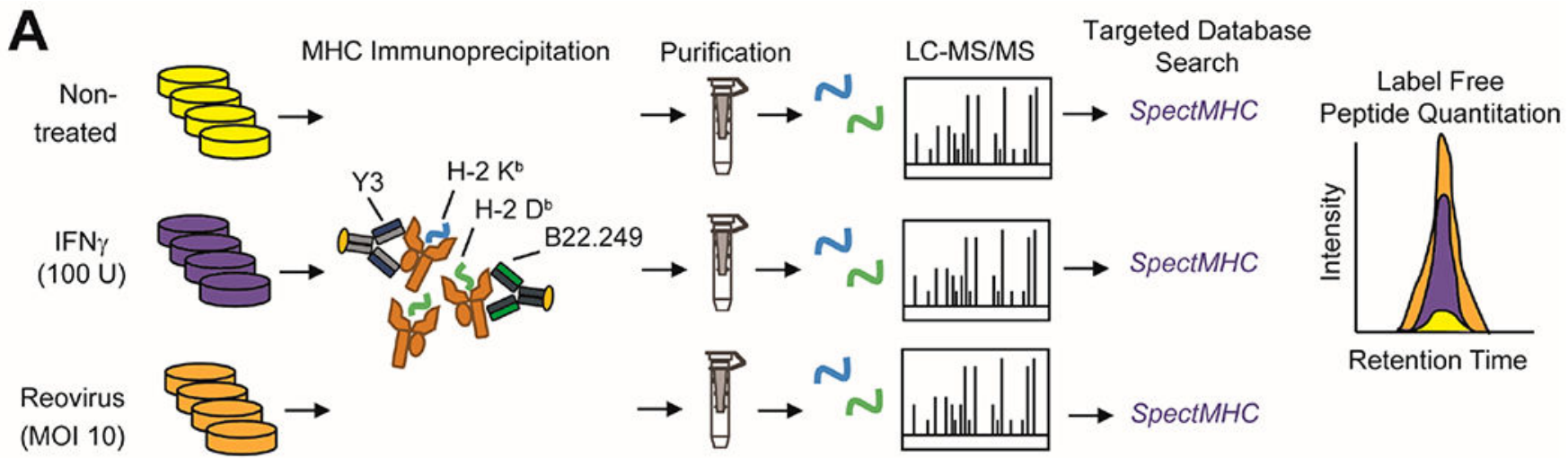

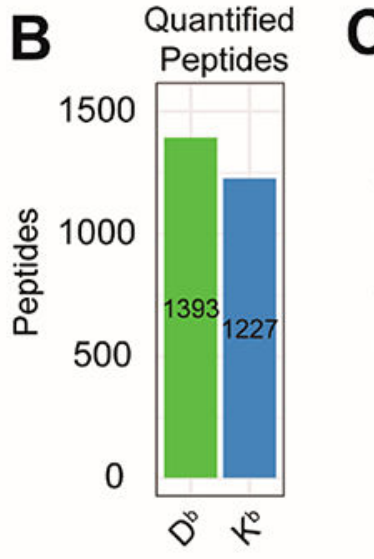

D

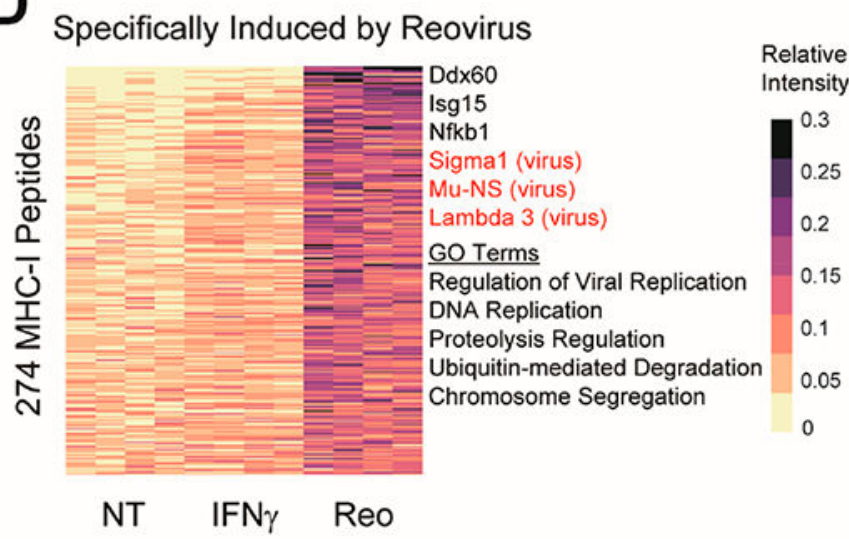

IFN $\gamma$ Regulated MHC-I Peptides

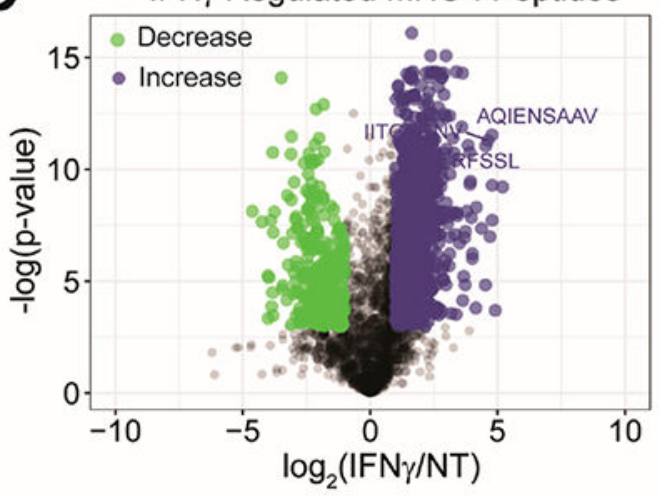

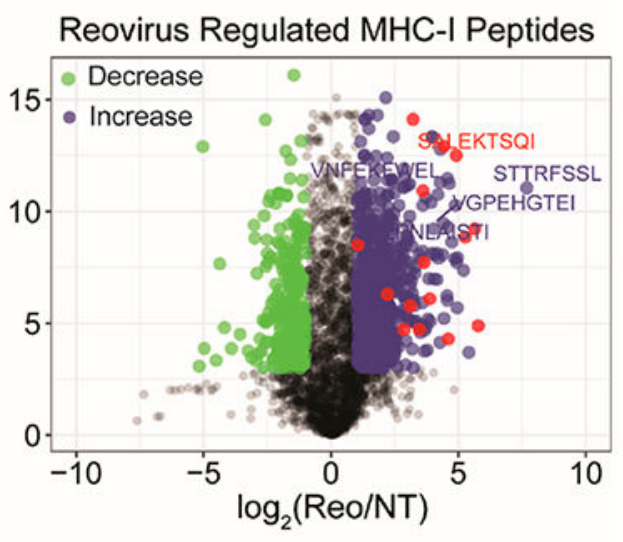

E

Induced by IFN $\gamma$ and Reovirus

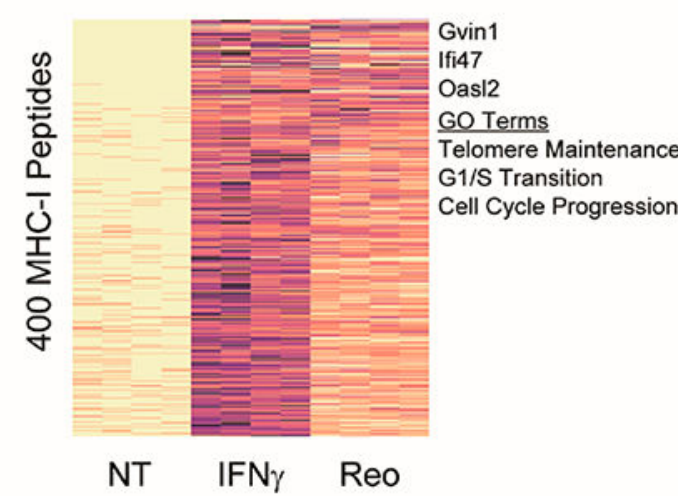

Relative Intensity

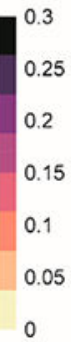

Figure 1.

Delineation of the reovirus-induced tumor MHC-I ligandome in vitro. (A) Schematic of the experimental setup. Mouse ID8 MOSE ovarian carcinoma cells $\left(1 \times 10^{8}\right)$ were treated for 24 $\mathrm{h}$ with IFN $\gamma$, reovirus (MOI 10) or left untreated. MHC-I peptides were immunoprecipitated with antibodies specific to the $\mathrm{H}-2 \mathrm{~K}^{\mathrm{b}}$ and $\mathrm{H}-2 \mathrm{D}^{\mathrm{b}} \mathrm{C} 57 \mathrm{BL} / 6$ mouse alleles and analyzed by mass spectrometry. Spectra were then identified with SpectMHC and compared across samples by label-free quantitation. (B) Total number of unique peptides specific to the $\mathrm{H}-2 \mathrm{D}^{\mathrm{b}}$ and $\mathrm{H}-2 \mathrm{~K}^{\mathrm{b}}$ mouse alleles that were quantified across the experiment. (C) Volcano plots of the IFN $\gamma$ and reovirus-regulated MHC-I peptides. Shown are the $-\log (p$-value $)$ based on F-tests ( $y$-axis) versus the $\log _{2}$ fold change (reovirus or IFN $\gamma$-treated/control) $(x$ - 
axis). Induced (blue dots) or repressed (green dots) peptides are those with normalized $\log _{2}$ fold changes $\geq 1$ or $\unlhd$ and $p$-values $\unlhd \mathbf{0} .05$ (adjusted using Benjamini-Hochberg multiple hypothesis correction). Peptides derived from reovirus source proteins are shown in red. (D) MHC-I peptides that are specifically induced by reovirus (mean $\log _{2}$ fold change $\geq 1$ and $p$ values $\$ 0.05$ ) and not by IFN $\gamma$ including several examples and enriched GO terms (biological process) pertaining to the source proteins. (E) MHC-I peptides that are induced by both reovirus and IFN $\gamma$ (mean $\log _{2}$ fold change $\geq 1$ and $p$-values $₫$ ).05) including several examples and enriched GO terms (biological process) pertaining to the source proteins. 


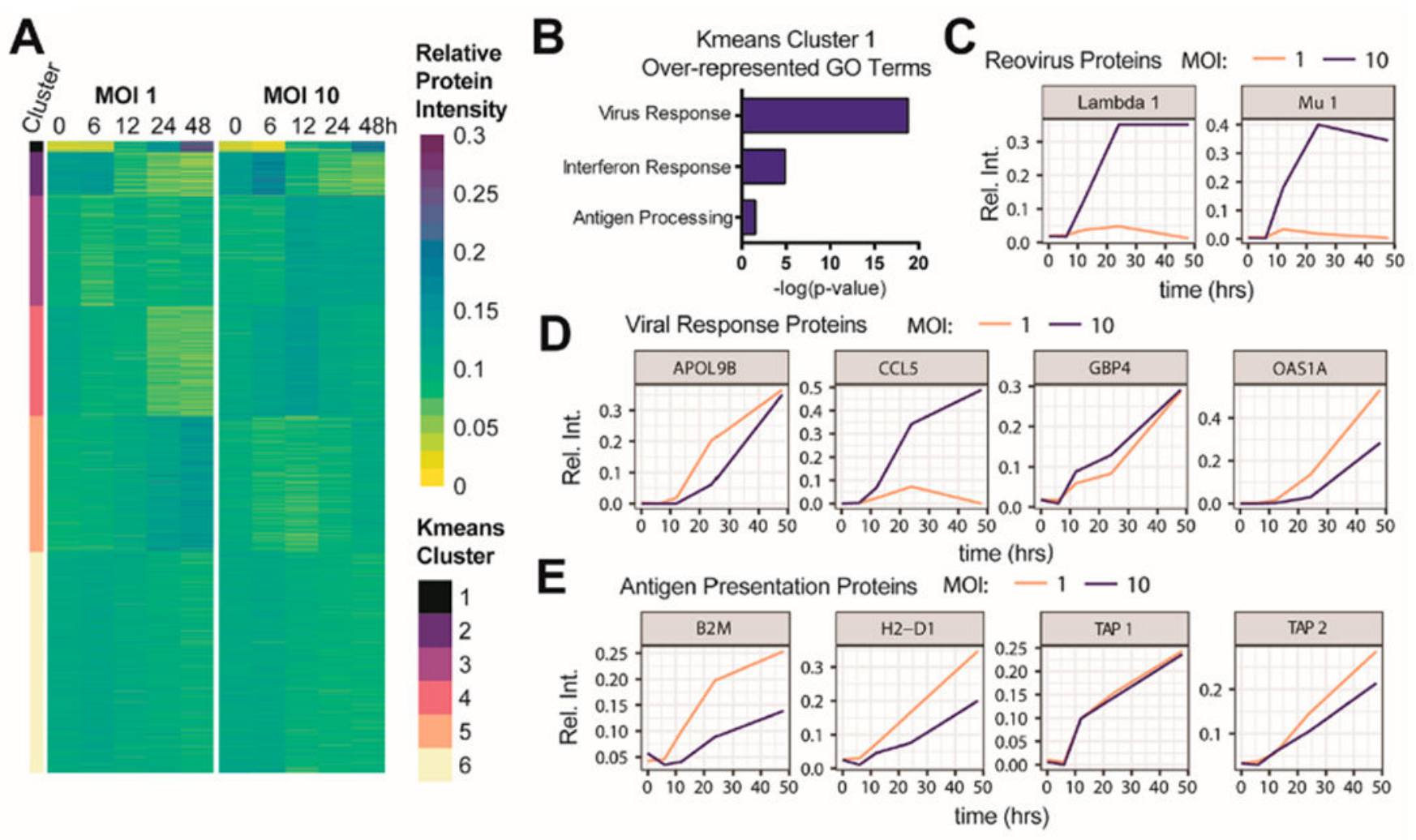

Figure 2.

Summary of temporal quantitative proteomics of reovirus-infected ID8 cells. (A) ID8 cells were harvested at five time points over $48 \mathrm{~h}$ of reovirus infection at MOI 1 or MOI 10 followed by multiplexed, quantitative proteomics using tandem mass tags (TMT). Shown is a heatmap with six k-means clusters (colored alongside) of the multiplexed relative temporal proteomics data set ( $n=6561$ proteins). (B) Enriched GO terms (derived using PANTHER) in k-means Cluster 1 (highly upregulated by reovirus) from A. (C) Temporal relative intensity from the proteomics data set of reovirus proteins Lambda 1 and $\mathrm{Mu} 1$ during the 48 $\mathrm{h}$ course of infection (MOI 1 and 10, five time points each). (D) Temporal relative intensity from the proteomics data set of representative viral response proteins (APOL9B, CCL5, GBP4, and OAS1A) during the $48 \mathrm{~h}$ course of infection (MOI 1 and 10, five time points each). (E) Temporal relative intensity from the proteomics data set of representative antigen presentation proteins (B2M, H-2D1, TAP1, and TAP2) during the $48 \mathrm{~h}$ course of infection (MOI 1 and 10, five time points each). 


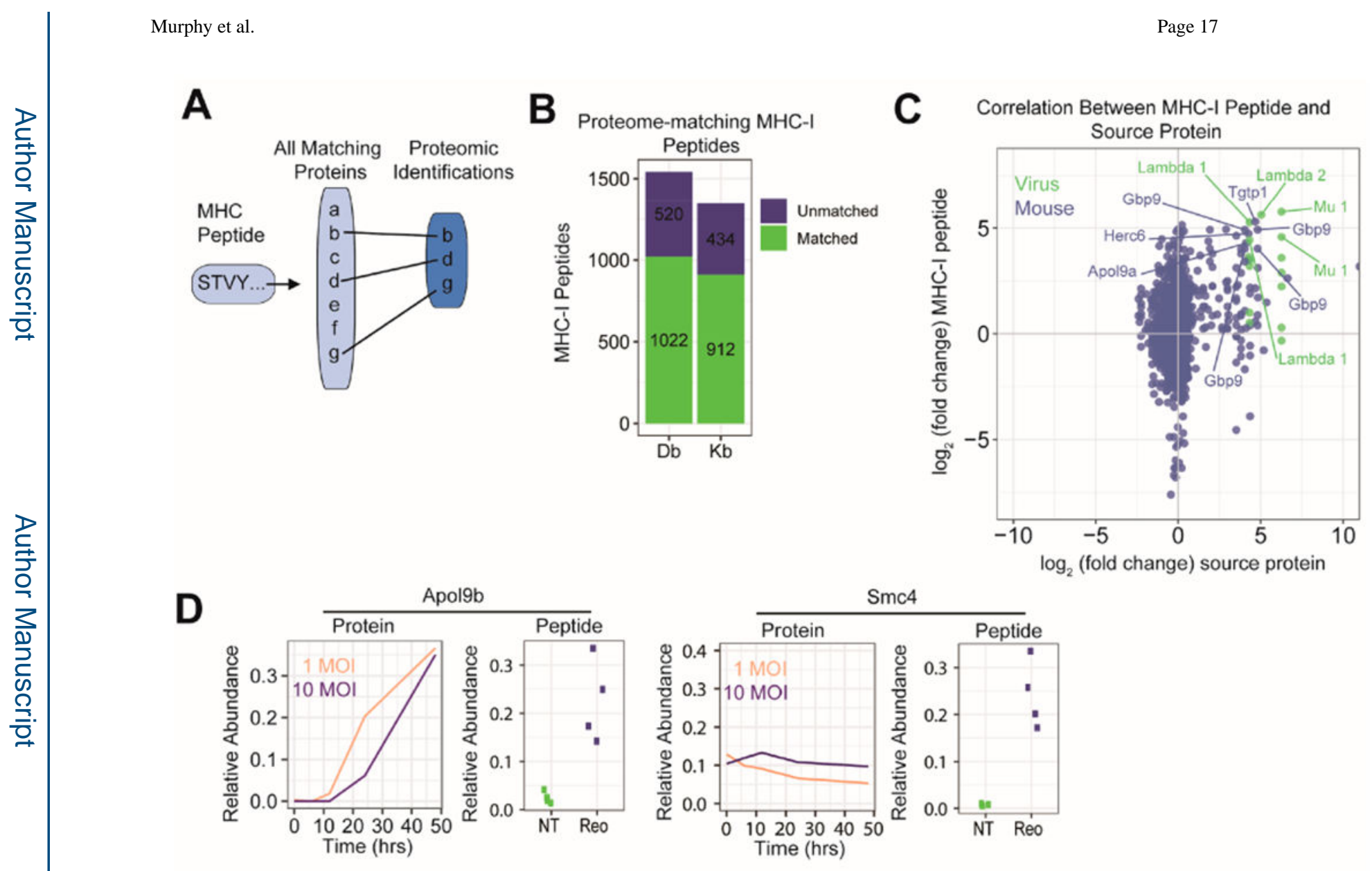

Figure 3.

Matching MHC-I peptide and source proteome quantitation during reovirus infection in ID8 cells. (A) MHC-I peptides were matched to all mouse protein accessions from the UniProt database and then these accessions were considered source proteins if they appeared in the proteomics data set shown in Figure 2. Some peptides match multiple source proteins. (B) Number of MHC-I peptides from the data set in Figure 1, for which protein matches were found (matched) or not found (unmatched) in the quantitative proteomics data set (both $\mathrm{H}-2 \mathrm{D}^{\mathrm{b}}(\mathrm{Db})$ and $\mathrm{H}-2 \mathrm{~K}^{\mathrm{b}}(\mathrm{Kb})$ specific MHC-I peptides). (C) Correlation of $\log _{2}$ ratios (Reovirus/Control) between MHC-I peptides from the MHC-I ligandome analysis from Figure 1 and their matching source proteins from the proteomics data set. Data are compared at $48 \mathrm{~h}$ of reovirus infection. (D) Representative examples of MHC-I peptides for which $\log _{2}$ ratios (Reovirus/Control) are correlated (APOL9B) and uncorrelated (SMC4) at the MHC-I peptide and source protein levels. 

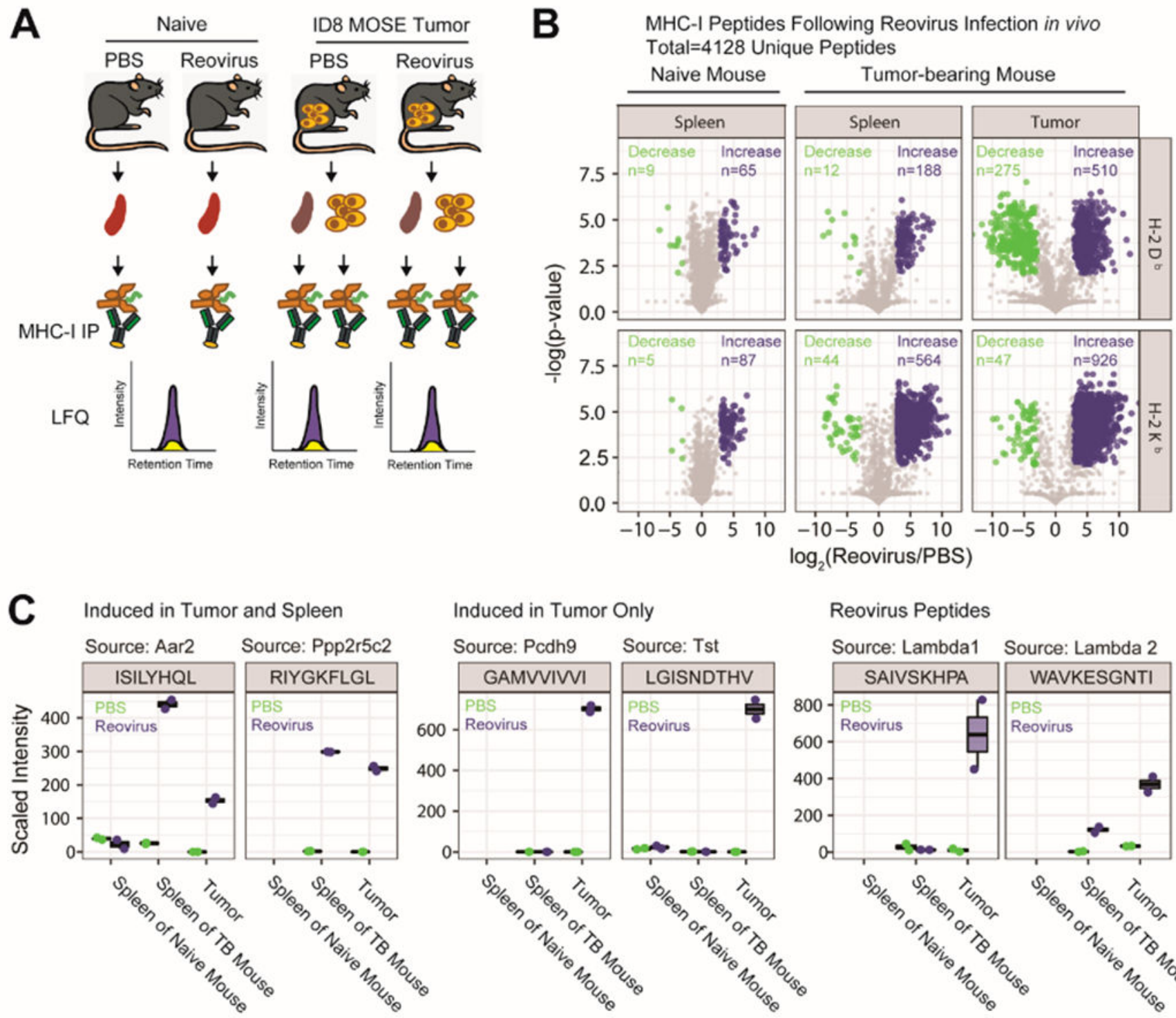

\section{Reovirus Peptides}

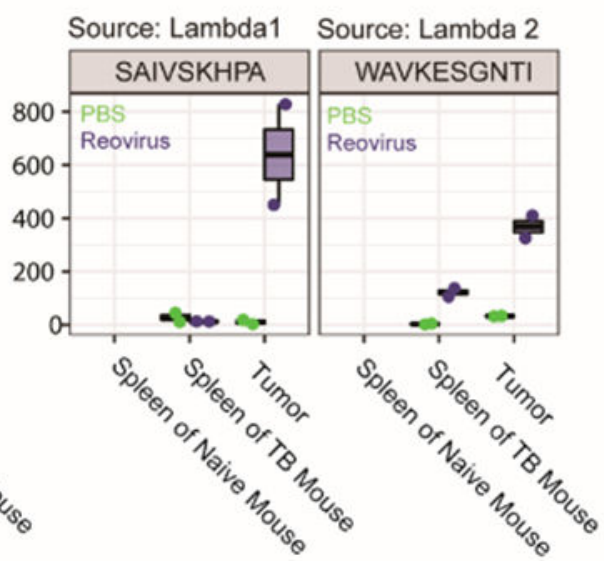

Figure 4.

Discovery of tumor MHC-I ligands in tumor and immune cells in vivo. (A) Experimental setup for in vivo MHC-I ligandome monitoring. Naive mice or those harboring ID8 MOSE tumor cells were injected with either PBS or reovirus $\left(5 \times 10^{8} \mathrm{PFU}\right.$, i.p.). Spleens and tumors (spleens only from naïve mice) were harvested at 7-10 days post injection and MHC-I peptides were compared by immunoprecipitation and LC-MS/MS with label-free quantitation. (B) Volcano plots for the number of increased (blue dots) and decreased (green dots) MHC-I peptides ( $\log _{2}$ fold changes $\mathfrak{3}$ or $\geq 3$ and $p$-values $\unlhd$.05) in the naive mice spleens, tumor-bearing mouse spleens, and tumors. The $-\log (p$-value $)$ is based on F-tests implemented in the $\mathrm{R}$ package genefilter and adjusted using Benjamini-Hochberg multiple hypothesis correction. (C) Representative examples of the MHC-I peptide intensities increased by reovirus across tumors or spleen of the tumor-bearing mice, but not in naïve mice. Shown also are intensities of example MHC-I peptides derived from reovirus source proteins quantified in the experiment. 
A

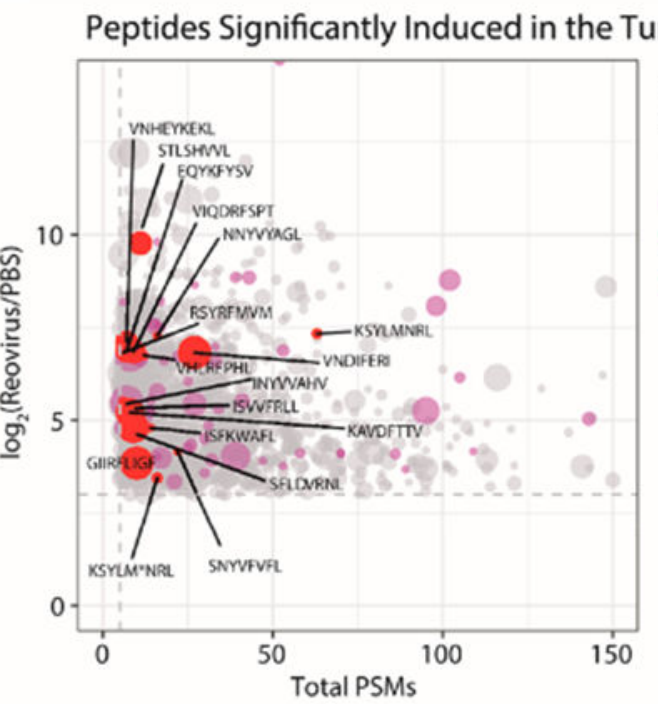

\section{mor}

NetMHC

$\%$ Rank

- 0.5

1.0

1.5

2.0

Up in Tumor

- Also Up in

Naive Spleen

- Selected

for IFN $\gamma$ assay

Splenic T cell IFN $\gamma$ Assay
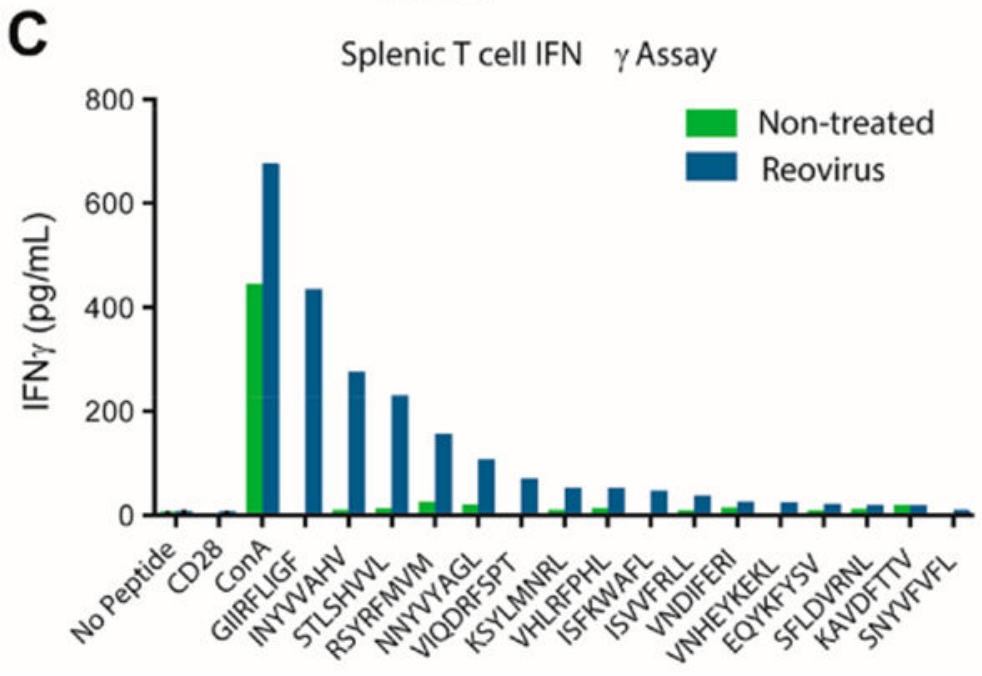

B Selected Peptides for IFNy Assay

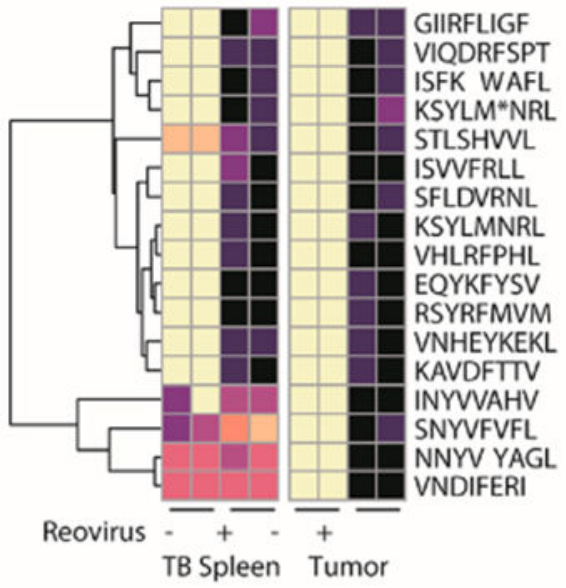

0.5

0.4

0.3

0.2

0.1

Figure 5.

Immunogenicity testing of reovirus-induced tumor MHC-I peptides. (A) Distribution of mean $\log _{2}$ fold changes, number of PSMs identified (as an indication for MHC-I abundance), and NetMHC \% rank for significantly induced peptides at the tumor from the data in Figure 4, showing the MHC-I peptides chosen (randomly) for validation by IFN $\gamma$ assay. Any MHC-I peptides also induced by reovirus in the naive spleen (shown in purple) were excluded from being chosen for IFN $\gamma$ assays. (B) Heatmap of relative intensity in the tumor and spleen of tumor-bearing mice of MHC-I peptides selected for IFN $\gamma$ assays (from the data in Figure 4). * = oxidized methionine. (C) MHC-I peptides from B were incubated with splenocytes collected from reovirus-infected and nontreated mice (both tumor-bearing). All incubations were done in the presence of CD28 stimulation, and concanavalin A (ConA, $2 \mu \mathrm{g} / \mathrm{mL}$ ) was used as a positive control. IFN $\gamma$ production ( $y$-axis) was determined by ELISA. 